\title{
The Practice of Deming Cycle Improvement Mechanism in Climate Change Environmental Education
}

\author{
Jyh-Harng Shyng* \\ Life Sciences College, Zhaoqing University, Zhaoqing city, Guangdong province, China \\ *Corresponding author: Assoc. Prof. Jyh-Harng Shyng, hidosing@outlook.com
}

\begin{abstract}
Cultivating environmental literacy is one of the most important tasks in the face of climate change. The purpose is to construct the general curriculum content of improving climate change adaptation to environmental literacy, and to plan the evaluation mechanism of learning effectiveness. The use of learning theory, Problem-Based Learning (PBL) theory and PlanDo-Check-Act (PDCA) cycle theory to improve the curriculum content and teaching continued to improve. This study focuses on the design courses from the three cognitive aspects of "conceptual cognition," "practical exercise" and "hands-on experience." Teach students how to cope with and respond to climate change to establish environmental literacy to mitigate the impact of natural reactions, and enhance awareness of environmental literacy by learning the science of climate adaptation and mitigation. The results of the actual implementation of the effectiveness assessment shows that, through student's feedback learning results, the courses presented gains for more, to know the appropriateness and necessity of curriculum planning, can be provided to the basic research of environmental literacy teaching curriculum planning.
\end{abstract}

Keywords: Environmental literacy; Climate change; Learning theory; Deming Cycle

Publication date: August 2021; Online publication: August 30, 2021

\section{Introduction}

Global warming and climate change have received tremendous attention from the international community over the past three decades. The Intergovernmental Penal on Climate Change (IPCC) announced at the $12^{\text {th }}$ meeting of Working Group I, who later contributed to the Fifth Assessment Report on Climate Change, namely "The current warming trend is of particular significance because most of it is extremely likely (greater than 95\%) to be the result of human activity since the mid-20th century [1]." Therefore, environmental warming mitigation and adaptation under climate change has become an increasingly important topic in the scientific community. It was recommended by the international community that this topic should be included in the liberal education among Taiwan's institutions of higher education, an essential part of the national environmental education, to improve students' environment literacy regarding climate change adaptation.

The objective of this research is to establish a diversified teaching and learning model, and by incorporating creative thinking and operational experience, to inspire and motivate students to think about problems concerning environmental literacy actively. With the concepts of mitigation, impact and adaptation, the author has designed a teaching model aimed to cultivate students' motivation for improving their own environmental literacy. 


\section{Literature review}

\subsection{Interrelationship between climate change "mitigation" and "adaptation"}

It was also mentioned in the Fourth Assessment Report by IPCC that the key issues of climate change lie in the scientific evidence, mitigation and impact adaption. These three issues interconnect with each other. The mitigation methods proposed by Jhong-Ming Liou concentrate on reducing the causes of climate change, and the adaptation methods focus on properly handling the impacts of climate change, both of which have influence on each other ${ }^{[2]}$. As pointed out by Liou, seven types of problems will entail global warming.

(1) Torrential rain, heatwave, drought, and other weather disasters.

(2) Ecosystem.

(3) Water resources.

(4) Agriculture and fisheries.

(5) Rising sea level, storm surge, coastline retreat and destruction.

(6) Infectious diseases and healthcare.

(7) Vulnerable groups.

The ultimate objective of the United Nations Framework Convention on Climate (UNFCCC), as set in 2013, is to stabilize greenhouse gas concentrations at a level that would prevent dangerous anthropogenic (human-induced) interference with the climate system; such a level should be achieved within a time-frame sufficient to allow ecosystems to adapt naturally to climate change, to ensure that food production is not threatened, and to enable economic development to proceed in a sustainable manner. Two strategies are proposed to deal with climate change: mitigation and adaptation. Their respective objectives are stated as below.

(1) Mitigation involves reductions in greenhouse gas emissions or the increase of greenhouse gas captured or stored by plants to slow down the progress or even reduce the scale of climate change.

(2) Adaptation refers to adjustments in natural or human systems in response to actual or expected climatic stimuli and their effects or impacts in order to moderate potential damages or to benefit from favorable opportunities. The objective of adaptation is to reduce the vulnerability of human and natural systems under climate change, hence minimizing the negative impacts they receive during extreme weather events and environmental warming and maximize the benefits when adapting to climate change.

The impacts of climate change can be seen from disasters, life-sustaining infrastructure, water resources, land use, coastline shift, energy supply and industry, agriculture and biodiversity, and healthcare. The environmental impacts of climate change cannot be overstated.

\subsection{Global trends of improving environmental literacy}

It is an urgent task for institutions of higher education in the 21 st century to inform their students of these crises, help them understand what lies at the center of them, reflect on the environmental ethics and their own responsibility under climate change, and equip them with basic knowledge, so that our mitigation policies can be further developed and more students will play their parts in our mitigation plan. Only in this way can we cultivate citizens who value our environment, and sustain a better planet for our future generation $^{[1]}$. 
The National Oceanic and Atmospheric Administration (NOAA) requires talents with climate literacy should possess the four aspects shown in Table 1., along with the seven basic contents of climate literacy that has been included in American National Science Education Standards. In this research, the author chooses to extend the definition of climate literacy to a broader one of "environmental literacy ${ }^{[2]}$."

Table 1. Climate literacy and its contents

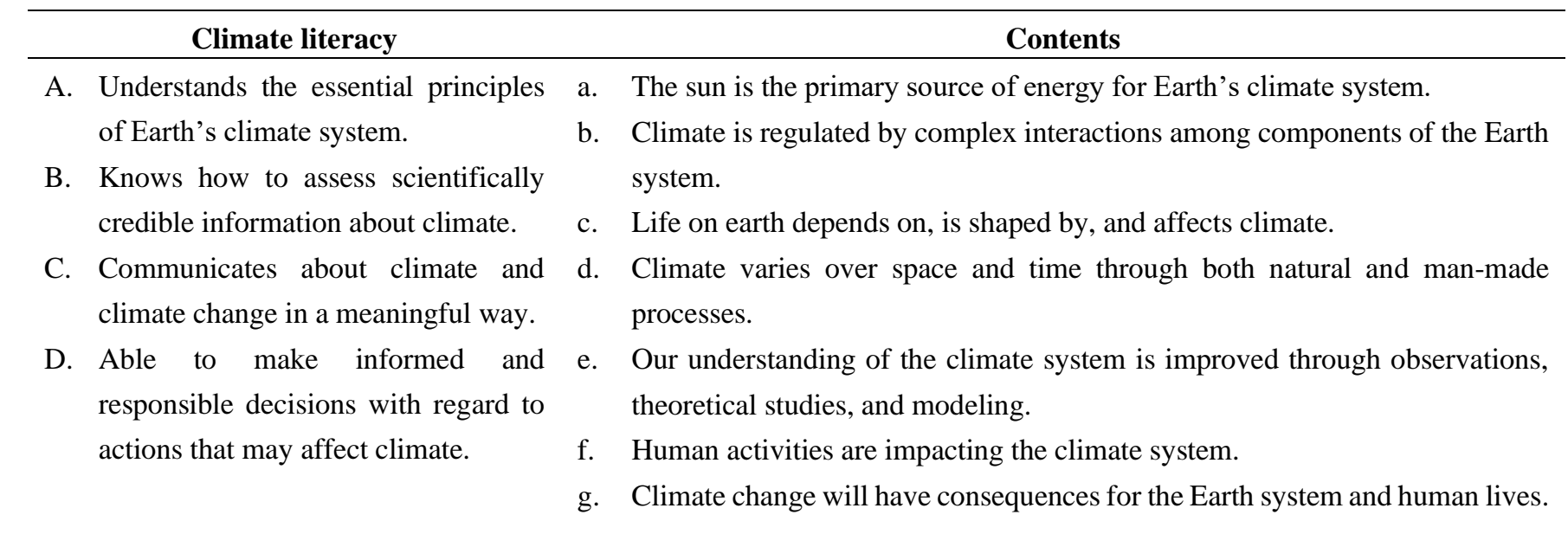

Sources: NOAA (2009), Climate Literacy - The Essential Principles of Climate Sciences, http://www.globalchange.gov/

\section{Theories applied in the course planning}

Three theories are applied in the course planning of this research.

(1) the learning theory drawing from one of the four main schema's of cognitive theory

(2) problem-based learning (PBL) theory

(3) PDCA cycle.

\subsection{Learning theory}

Learning theory emphasizes the importance of social context on a person's social behaviors. It believes that social behaviors are acquired by observing and imitating others, and the person's past learning experience contributes to today's emotions, attitudes and behaviors [3]-[4]. Traditional computer-assisted teaching methods us behaviorism as the theoretical principle, as represented by sequencing. With the advancement of modern psychology, cognitive psychology that explores human learning and cognition, has become the mainstream of contemporary psychology. Therefore, the multimedia teaching system chose cognitive psychology as its theoretical basis. However, in recent years, with the rise of the Internet, the focus of educational technology has shifted from cognitive psychology to constructivism, forming a completely new school $^{[5]}$.

As a branch of pedagogy and educational psychology, learning theory describes or explores the types, processes of human learning, as well as the conditions that can lead to effective learning. As pointed out by Liang-Fang Shih, the term "learning" in psychology has a different meaning from how we understand it in daily life ${ }^{[6]}$. So far, the psychology community has not yet reached a consensus on the meaning of this term. Students of learning theory gave out their definitions.

They can roughly be divided into four schemas. Include: "Behaviorism, Cognitivism, Constructivism, Humanistic, Psychology." 


\subsection{Problem-based learning or PBL}

Problem-based learning or PBL is a new approach to learning. Students are instructed to conduct autonomous learning with simple life-related examples, group discussions and problem-solving practices. Currently is one of the major directions for education educational method (medical) research. Related research can be summarized as follows:

(1) Barrows \&Tamblyn hold the belief that PBL should be a learning approach in which a problem is first put forward with a scenario, and then the students follow some systematic steps to solve the problem ${ }^{[7]}$. The American medical educator Professor H. S. Barrows once applied PBL during the teaching of medical students, and significantly improved the students' problemsolving ability.

(2) Professor E. W. Bridge from Stanford University and Professor P. Hallinger from Vanderbilt University applied PBL to the training of administrative faculty. The learning method proves to be of great help to the students in career development.

(3) As pointed out by Fogarty, PBL is a curriculum model where real-life problems are utilized as the impetus and students will be guided by ill-structured and open-ended problems ${ }^{[8]}$.

(4) Levesque conducted a literature review and concluded that PBL is a student-centered curriculum delivery method, where students can obtain information in different ways to solve the problems, including group discussion, via various technology or self-study ${ }^{[1]}$.

(5) Peter, Stewart \& Graham defined PBL as "a learning method where students first encounter the problems, and then solve them in a systematic and student-centered exploration process. The problems guide students through their learning of information and concepts, which in fact is more important than solving the problem itself ${ }^{[11]}$."

Based on the views of constructivists, PBL believes learning is a process of constructing our knowledge system in a social environment rather than just a process of acquiring knowledge.

\subsection{Plan-Do-Check-Act Cycle (PDCA Cycle), or the Deming Cycle}

The Plan-Do-Check-Act Cycle proposed by William Edwards Deming, or the PDCA cycle is a cycle devised for quality management ${ }^{[12]}$. The procedures of planning, doing, checking and acting will be followed to ensure the reliability of the work and constantly promote the quality. The four procedures are not a one-time process. Instead, they are a cyclical process, with another problem arising after one is being solved ${ }^{[13]}$.

The PDCA cycle has shown a significant effect on quality management. It is a constantly improving model with four repeated steps that could lead to continuous quality improvement and constant learning ${ }^{[13]}$. The four steps in a "PDCA cycle" are as follows:

(1) Plan $(\mathrm{P})$ : Determine the principle and objective and come up with a plan.

(2) Do (D): Conduct the plan in reality.

(3) Check (C): Review the results and figure out the existing problems.

(4) Action (A): Process the check result. Successful experience should be promoted and standardized, while the failure should be reviewed to avoid recurrence. The unresolved problems will be included in the next PDCA cycle. 


\section{Course planning of environmental education tackling the climate change}

With an aim to design a liberal education course, this research focuses on the natural disasters caused by global warming. The courses and teaching contents are organized based on relevant theories.

Course planning approach: Through the learning effect evaluation management of the course, the teacher will deepen the students' understanding of global warming and climate change. The students will be encouraged to know more about the mitigation and adaptation to tackle climate change so that they can accumulate more "environmental literacy" through the knowledge-seeking process of the designed course. It shown in Figure 1.

In the PBL teaching mode, the teacher focuses on practical problems and encourages the students to conduct group discussions with an aim to stimulate students' active learning, critical thinking and problemsolving abilities. Based on the PBL teaching mode, the author constructs the core concepts of course planning and execution. The learning effects of the students can be divided into three aspects.

(1) Cognition: be aware of the urgent need to conserve and recycle natural environment resources; obtain a concrete understanding of disaster prevention in daily life; and further observe and deepen the understanding of environmental resources reservation and recycling.

(2) Practice: strengthen practices according to the specific requirements and use creativity and practices to experience the process of education concerning environmental protection and disaster prevention.

(3) Experience: experience the concrete effect of environmental protection by the process of being informed, understanding, learning and execution.

The students will be taught to think of the question that under the current trend of climate change, as members of the modern society, how should they react to the adaptive activities for environmental protection in daily life? activities for environmental protection in daily life?

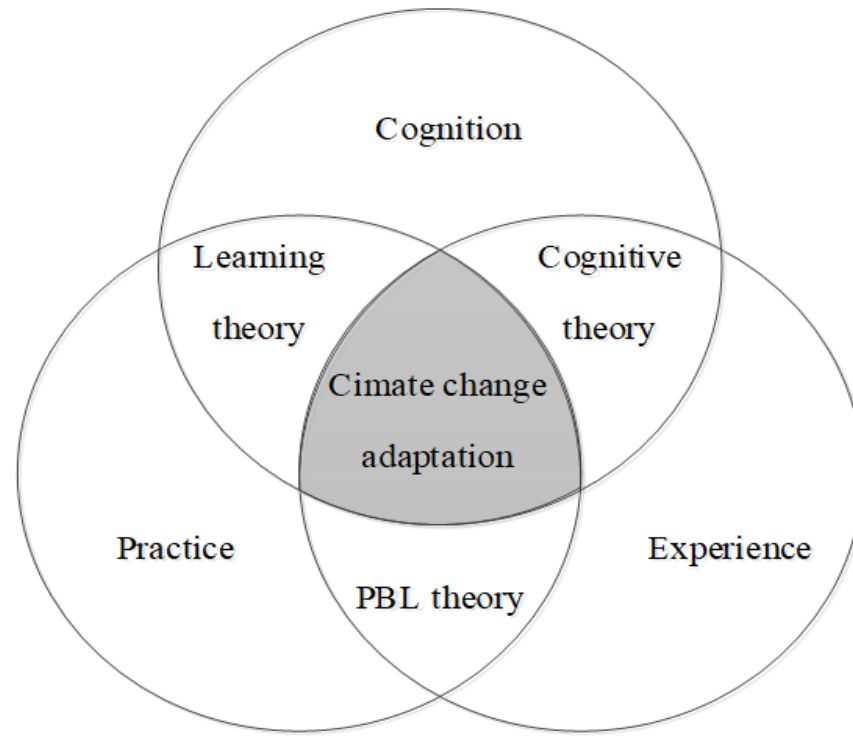

Figure 1. Planning concept of environmental literacy courses on climate change

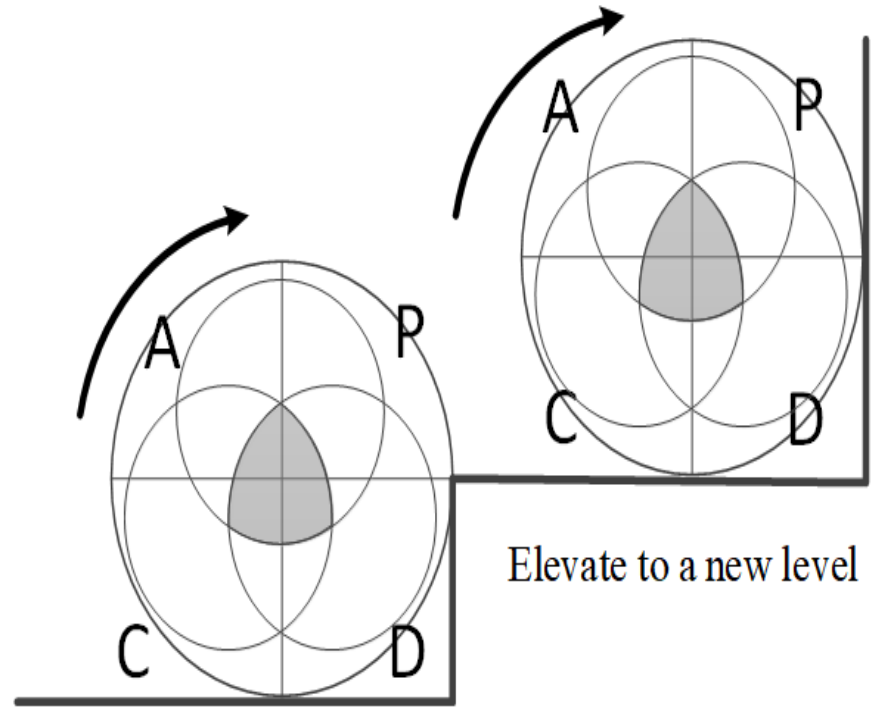

Figure 2. The self-improving PDCA cycle for courses on environmental literacy

As for the execution, the PDCA cycle will be used to constantly update the teaching mode. It shown in Figure 2. Through the course, students will know more about the impact of various disasters caused by climate change on the environment and establish their understanding of science and environment. Also, by 
organizing discussions on related topics and videos, the teacher can deepen their understanding of natural forces, and raise their awareness of cherishing resources on the planet. During the discussion on different environmental issues, the students will be encouraged to think deeper on the issues, so they can have a stronger thinking ability on the tissue of "climate change adaptation."

\section{PDCA Cycle process improvement for courses concerning climate change}

\subsection{Environmental literacy and course plan introduction (plan)}

The PDCA cycle is a process of transforming knowledge into practice. Since the PDCA cycle has shown significant effects on quality improvement during the manufacturing process, a "four-stage, eight-step" approach can be followed. During the execution, it is worth noted that any conclusions should be based on facts and rational analysis should be conducted using statistical tools. The purpose of the course planning in this research is to elevate the teaching effect of the environmental literacy course. The four steps in a PDCA cycle are used to construct the course planning framework to continuously improve the quality of the course. It shown in Table 2.

Table 2. Description of the course planning framework based on the PDCA cycle

\begin{tabular}{|c|c|}
\hline Stage & Measures \\
\hline Plan (P) & $\begin{array}{l}\text { - During the pre-planning of the course, the adaptation of urban disaster prevention in urban areas under climate } \\
\text { change serves as the main axis for the course design } \\
\text { - During the late planning of the course, the environmental literacy under climate change adaptation serves as } \\
\text { the theme and main axis for the course design }\end{array}$ \\
\hline Do (D) & $\begin{array}{l}\text { - Map-making for earthquake and disaster prevention drills on the campus } \\
\text { - Visit to the demonstration base for green building education } \\
\text { - Shooting environmental protection micro-films }\end{array}$ \\
\hline Check $(\mathrm{C})$ & $\begin{array}{l}\text { - Self-evaluation form and inter-group peer evaluation mechanism } \\
\text { - Learning outcomes uploaded to online teaching platforms for mutual exchanges and learning } \\
\text { - Mid-term map-making for disaster prevention } \\
\text { - Film production at the end of semesters } \\
\text { - Statistical analysis for learning effect evaluation }\end{array}$ \\
\hline Action (A) & $\begin{array}{l}\text { - Evaluate students' learning effects to check if the course contents are properly arranged } \\
\text { - Develop basic contents for future courses }\end{array}$ \\
\hline
\end{tabular}

As one of the courses of the "Healthcare in Climate Change Adaptation" series designed for Taiwan's educational institutions, our course takes in teachers with professional backgrounds in property management, environmental medicine, stone and building material maintenance. Their participation in the course is shown as follows: 5 weeks of collaboration with experts in property management, 4 weeks of collaboration with experts in stone and building material maintenance, and 7 weeks of teaching in environmental literacy.

\subsection{Course execution (Do)}

Besides teaching audio and visual courses, we also organize group practice to monitor the students' learning achievements. Industry leaders are invited to give them professional guidance. We mean to combine the teaching of professional knowledge and actual practices. Community practices will be organized in the middle and at the end of the semester. Hopefully, students will exhibit excellent performance after group discussions, practices and teaching from the industry leaders. 
Our course is designed for undergraduate students, ranging from freshmen to seniors. Due to the broad range of our students, a mentorship system is introduced where the juniors and seniors can guide freshmen and sophomores through the process of practice. Industry leaders are brought in to provide assistance in the course teaching and community practices to improve their performances under professional instruction. We encourage students to share their thoughts and opinions with the teachers under one-on-one instruction, so that the teachers and students can learn from each other.

We divide the course execution for a semester into three stages. In the first stage, group discussions on some issues are conducted for interactive learning. The learning manual will be filled out and the learning results submitted. In the second stage, students are divided into groups to conduct professional practices and community practices on environmental protection. In the third stage, students are asked to review their performance and fill out the learning achievement manual.

\section{Learning outcome evaluation with environmental literacy questionnaire (check) 6.1. Standards for evaluating learning effects}

Tests (pre-test and post-test) are conducted with the climate change adaptation literacy test and questionnaire for Taiwan's higher education institutions as the benchmarks. The tests are conducted before the course starts and after the course ends. Through the course's execution process, the students have already understood the basic knowledge concerning climate change. The contents of the questionnaire are designed as follows:

(1) learning attitude;

(2) action/skills;

(3) professional knowledge; including six aspects:

a. the impact of climate change on human health and its adaptation;

b. the impact of rising air temperature on human health and its adaptation;

c. the impact of climate change on vector-borne diseases and its adaptation;

d. the impact of climate change on water-borne infections and its adaptation;

e. the impact of climate change on air-pollution-related diseases and its adaptation;

f. the impact of climate change and health management strategies.

\subsection{Pre/post-test results of learning effect evaluation}

(1) Family background affecting students' environmental literacy.

As for the students' family background, fathers with a college degree take up the most, accounting for $59.5 \%$, while most of them have a mother who has never been to high school. As for their occupation, $61.9 \%$ of the parents work in agricultural, manufacturing and commercial industries. We asked if the students have ever been exposed to any basic concepts of climate change, $100 \%$ of the respondents answered negatively, indicating that there is a missing link about environmental literacy in family education.

(2) Club activities affecting students' environmental literacy

None of the students we interviewed have ever joined any clubs related to environmental protection inside or outside the campus. Since they can't get it from club activities, it means students can only obtain relevant information from what they are taught in college. 


\subsection{Analysis of the students" "learning attitude" and "action/skills"}

When we conducted the questionnaire surveys on the students, we found a significant improvement on their "learning attitude" and "action/skills". As indicated by our analysis, in terms of learning attitude, our students were alerted of the fact that current technology is still not able to solve the issue of climate change; they can come up with their thoughts on environmental issues and have acquired environmental literacy related to their majors and knowledge about how adaptations can reduce damages.

With regards to action/skills, our students now pay attention to the warning signs and adaptation measures related to climate change; they are willing to absorb knowledge outside their fields to gear themselves up for adapting to environmental impacts; they are also aware of the fact that higher air temperature will negatively impact outdoor activities.

\subsection{Analysis of the professional knowledge of the students}

As for "professional knowledge" of environmental literacy such as the vulnerability issue of climate change, mosquitoes as disease vectors, water resources, air pollution and healthcare management and afforestation as an adaptive measure, both the results of the pre- and post-test increased by 46.8 points. Among them, the most significant increase was seen in healthcare management and afforestation as an adaptive measure, due to the fact that most of the campus students are living in urban areas and such aspects of environment literacy are related to their living conditions.

Reliability analysis was conducted on the post-test questionnaires. The Cronbach's Alpha value stood at 0.91 , indicating that the students' learning attitude and action/skills significantly impact students' learning about climate change. In terms of "professional knowledge", the average score of the students before the test was 47.33, while the score after was 49.13. The significant improvements in students' performance indicated that the planning of this course was suitable and highly integrated into the building of students' environmental literacy.

\subsection{Actions}

(1) Students can only access climate change-related information through newspapers, magazines and TV programs, for such information is absent in the family they grow in.

(2) During the course, teachers can encourage the students to share the basic knowledge on climate change with their families, which shall be the first step in disseminating climate change knowledge to ordinary families.

(3) Junior college students are not motivated enough to take part in activities related to climate change. Nearly no clubs advocating environmental protection are formed spontaneously by students. The school can organize reading parties, environmental seminars and workshops to inform them of more environmental knowledge. It will surely be of help to the students' future career development.

(4) By enhancing their own environmental literacy of learning attitude and actions/skills, students can incorporate the concepts of environmental health, environmental protection, and green in the industries and workplaces where they will work in the future.

(5) Knowledge of the supplementary teaching materials will be presented during the course, including vulnerability issues of climate change, mosquitoes as disease vectors, water resources, air pollution and healthcare management and afforestation as an adaptive measure, etc.

(6) If the students encounter some new topics we did not present enough in class, or topics they want to learn more about, they can write them down on the learning manual. We will continuously adjust our teaching contents based on what they wrote. 


\section{Conclusion and suggestions}

In this research, the environmental literacy course was planned and arranged to present the students with the impact of climate change. By doing this, we aim to inform our students of the severe impacts of climate change and the strategies of mitigation and adaptation to tackle the environmental issue. Through audio and visual courses, expert lectures, group discussions, group practices and community learning, students can achieve expected learning effects after taking our course. The major conclusions we reached before and after the course are as follows:

(1) Our course is constructed based on the learning theory and the PDCA cycle. It is a self-improving course that provides basic knowledge on climate change adaptation and environmental literacy.

(2) The execution of the teaching activities was in line with the course theme. Different teaching methods and theories are applied in each stage. Execution in the course includes nine lectures, two audio-visual teaching courses, three group discussions, two group practices, two expert lectures and seven-time assignments of filling out the learning manual, among others.

(3) A post-test questionnaire survey was conducted when the course was over. Significant improvement can be seen in students' "learning attitude" and "action/skills"; With regards to professional knowledge, the students scored an average of 47.33 points. When the course was over, the number stood at 94.13 points, an increase of 46.8 points, a perfect demonstration of the course's smooth execution and effective nature.

Based on the content reviews and teaching evaluation the students filled out in the learning manual. They tend to rate our course as "highly rewarding", indicating that our course planning is appropriate and necessary.

\section{Disclosure statement}

The author declares that there is no conflict of interest.

\section{References}

[1] Tsai HM, 2013, Climate Change and Environmental Ethics, Taipei: The $102^{\text {nd }}$ Teacher Training Camp for Climate Change Adaptation Among Institutions of Higher Education Under the Ministry of Education of the Republic of China.

[2] 2009, NOAA. Climate Literacy-The Essential Principles of Climate Sciences. http://www.globalcha nge.gov/

[3] Taylor, Shelley E, et al., 2006, Social Psychology. trans. Man-Ling Jhang. Taipei: Yeh Yeh Book Gallery.

[4] Chen JM, et al., 2006, Social Psychology. Taipei: Yeh Yeh Book Gallery.

[5] Gao SF, 2002, The Fundamental Theory in E-learning The Journal of Design Research, (2).

[6] Shih LF, 1996, Learning Theory: Theories and Principles of Learning Psychology. Taiwan: Liwen Cultural Group.

[7] Barrows S, Tamblyn RNH, 1980, Problem-Based Learning: An Approach to Medical Education. New York: Springer.

[8] Fogarty R, 1997, Problem-Based Learning and Other Curriculum Models for the Multiple Intelligences Classroom. Arlington Heights, Illinois: IRI/SkyLight Training and Publishing, Inc. 
[9] Levesque A, 1999, Comparison of Problem-Based Learning and Traditional Lecture Methods on Medical Student Performance. University of Houston.

[10] Zheng YL, 2006, Courses and Teaching of Problem-Based Learning. Journal of Diwan University, (1): 177-95.

[11] Peter S, Stewart M, Graham W, 2001, Problem-Based Learning: Case Studies, Experience and Practice. London: Kogan Page Limited.

[12] Deming WE, 1986, Out of the Crisis. MIT Center for Advanced Engineering Study Cambridge.

[13] Dai JY, 2005, Total Quality Management, Tsang Hai Publishing. 